\title{
Effect of Screen-Time on Sleep Pattern and Dietary Habits among College- Going Students in COVID-19 Pandemic
}

Rahul Saxena ${ }^{1}$, Nitesh Parmar ${ }^{2}$, Prabhleen Kaur ${ }^{3}$, Tanu Allen ${ }^{4}$

${ }^{1}$ Student B.Tech+ M.Tech (BT) Dual Degree, Amity Institute of Biotechnology, Amity University Uttar PradeshNoida, Sector- 125, Noida, Uttar Pradesh, India, 201313; ${ }^{2}$ Student B.Tech+ M.Tech (BT) Dual Degree, Amity Institute of Biotechnology, Amity University Uttar Pradesh-Noida, Sector- 125, Noida, Uttar Pradesh, India, 201313 ${ }^{3}$ B. Tech (BT), Amity Institute of Biotechnology, Amity University Uttar Pradesh-Noida, Sector- 125, Noida, Uttar Pradesh, India, 201313; ${ }^{3}$ Assistant Professor, Amity Institute of Biotechnology, Amity University Uttar PradeshNoida, Sector- 125, Noida, Uttar Pradesh, India, 201313

\begin{tabular}{|c|c|c|c|c|c|c|c|c|}
\hline Abstract & Introduction & Methodology & Results & Conclusion & References & Citation & \multicolumn{2}{|c|}{ Tables / Figures } \\
\hline \multicolumn{9}{|c|}{ Corresponding Author } \\
\hline \multicolumn{8}{|c|}{$\begin{array}{l}\text { Dr. Tanu Allen, Assistant Professor, Amity Institute of Biotechnology, Amity University Noida Uttar } \\
\text { Pradesh- } 201301 . \\
\text { E Mail ID: tallen@amity.edu }\end{array}$} & 口ifing \\
\hline
\end{tabular}

\section{Citation}

Saxena R, Parmar N, Kaur P, Allen T. Effect of Screen-Time on Sleep Pattern and Dietary Habits among CollegeGoing Students in COVID-19 Pandemic. Indian J Comm Health. 2021;33(1):65-74.

https://doi.org/10.47203/IJCH.2021.v33i01.009

Source of Funding: Nil Conflict of Interest: None declared

\section{Article Cycle}

Received: 01/11/2020; Revision: 29/11/2020; Accepted: 12/12/2020; Published: 31/03/2021

This work is licensed under a Creative Commons Attribution 4.0 International License.

\section{Abstract}

Background: Optimum and good quality of sleep are pertinent to the health and equilibrium of biological functions. Increased use of electronic gadgets for academics and social interactions during the COVID-19 pandemic has extended the screen time of students, affecting sleep and eating patterns. Aim \& Objective: To study the association of extended screen time on sleep pattern and calorie intake among college students during the COVID-19 pandemic. Settings and Design: Observational study was conducted using 'Google forms' to collect data on sleep and food intake among 60 college-going students. Methods and Material: Google form composed of questions related to demographic, anthropometry, screen time, sleep quality (PSQI) \& dietary pattern (food frequency questionnaire) and tied to written consent was sent via WhatsApp to college students. Statistical analysis used: Data were grouped based on the screen time $>10 \mathrm{hrs}$ and $</=10 \mathrm{hrs} /$ day. Independent " $\mathrm{t}$ " test, Chisquare test and Mann Whitney test were used to compare the sleep domains scores and calorie intake. Results: With an average screen time of $10.9 \mathrm{hrs}, 38 \%$ of students were using the screen maximally during the night. Poor Sleep Quality was (PSQI Score $>5$ ) observed in $80 \%$ of the college students, with $46.6 \%$ having a sleep of $<5$ hrs/day. Students' calorie intake was ten times the recommended daily requirement during the stay at home but was negatively related to screen-time, though non-significant. Conclusions: The study concludes that average screen time of students of age group 18-24 years have increased during night under the lockdown. This extended viewing in night has shifted the sleep circadian cycle to morning hours, with daytime sleepiness and poor sleep quality. The high calorie intake was also observed in students during lockdown though no correlation was established with the screen time and sleep quality.

\section{Keywords}

Screen-Time; PSQI; Calorie Intake; College Students; COVID-19 


\section{Introduction}

Sleep is a physiological process that is important for an integral optimum functioning of our body. Ideal and good quality of sleep is pertinent for an individual's health and well-being and to maintain the delicate equilibrium of biological functioning of our body. Indeed, it plays a critical role in cognition and memory and governs cells' homeostasis through secretion of hormones.(1) Poor sleep quality is nonrestorative and is a key symptom of several psychiatric disorders, insomnia(2) and chronic illness.(3) Scientific evidences by epidemiological studies have observed the association of sleep disorders with cardiovascular mortality,(4) stroke,(5) impaired glucose tolerance, and immune dysfunction(6). Disharmony of sleep cycles leads to an aberrant release of feeding hormones causing desynchronization of time-restricted feeding and nutritionally driven rhythms affecting the dietary pattern and associated determinants.(7)

Sleep pattern maturation and its neurobiological regulation occur during adolescence with the sleep duration requirement changing with age (8) and are recommended for age group $>18$ years are $7-9$ hours.(9) Poor sleep quality in college students is reflected as daytime sleepiness (10) and fatigue associated with poor concentration, cognition (11) and emotional dysfunction (12) which contributes to deprived academic and learning skills (13) and physio-psychological health. (14) Among the causes for sleep disturbances, screen time and lightemitting devices used during late hours play a major role.

College life is a transition period from teenager to responsible, mature adult both physically and mentally. With the increased stress of performance and achievement, gadgets and accessibility to several social platforms have increased both for personal and academic purposes.(15) Also, the advancement of teaching-learning devices in this modern era is increasing the screen time among college students is inevitable.

The current pandemic of COVID-19 has presented an unnatural situation to educational teaching due to the several countries' lockdown measures. With the restriction of physical movement, online teaching has been initiated to keep up with their academics. Social distancing and online teaching have increased the use of the screen of electronic gadgets in collegegoing students.

\section{Aims \& Objectives}

To measure average screen time and its effect on sleep quality and dietary pattern to initiate appropriate measures to minimize the change.

\section{Material \& Methods}

This cross-sectional online study was conducted during July and August 2020 among college students of age group $18-24$ years of universities in and around Delhi, undertaking online classes for their academics from home. Participants for this online survey were included following their written informed consent. A sample of 60 participants was included by convenient sampling. The study was conducted using Google form (https://forms.gle/FBotEEyoCZxxVvBBA ). The first section of the form contained the consent along with additional information regarding the principal investigator and the institute involved. Those participants consenting by selecting the "yes" option were directed to the second section of the form containing the questionnaire.

The data collection tool- consisted of 12 questions related to demographic, screen time, dietary pattern of the participants, and anthropometric parameters. The questions were closed-ended with some single responses and multiple response options. The answers to the questions in the questionnaire were self-reported.

Screen time (ST) is the amount of time spent using a device with a screen such as a smartphone, computer, television, or video game console.(16) An 18-item screen time questionnaire (17) was used to quantify the use of such screen-based devices which had Likert scale. The screen time cut off was taken as 10 hrs per day considering the maximum hours of screen time accepted for the adolescent's (18) and the participants were grouped based on it.

A validated questionnaire for sleep [PSOI] (19) was used to observe the sleep pattern and score the components of sleep quality.

A food frequency questionnaire (20) was used for the collection of caloric intakes was opened for responses. All questions were required to be answered before submission. No change in response was allowed post submission. During analysis personal identifiers were excluded to make the survey anonymous. 
The link for the google form was sent to the potential study participants using social media (WhatsApp). The response was automatically captured and entered in MS EXCEL 365 for analysis. The data was collected over a period of one month (August 2020). Data was entered using MS EXCEL 365 for and statistical analysis was conducted by using SPSS 20. Correlation between variables of components of global sleep score, screen time and calorie intake were done using Pearson and Spearman test for correlation. The level of significance was set at $<0.05$ for the inferential statistics.

\section{Results}

An equal proportion of males and females were there in the study participants. The mean BMI of the study population lies in the overweight range as per the Asian criteria for non-communicable diseases. During the lockdown period of this pandemic the average calorie intake of 15782.05 calorie/day among college students was much higher than the average calorie required for them as per the RDA with the moderate physical activity the age group. Mean total screen time per day is on the higher than the recommended screen time of 4-9 hrs. of day(9) for the college students. Overall average Sleep score was observed to be on the high, suggesting the moderately poorer quality( 21 )of sleep by the college students during this COVID-19 pandemic. (Table 1) Based on the average screen time for college students of 4-9 hrs. /day (9) and considering one hour of deviation beyond the maximum value, a cut off of $10 \mathrm{hr}$./day was decided to categorize students into two groups. No significant difference was observed between age, BMI calorie intake/day and global PSQI score were observed among students with Screen time $>$ than $10 \mathrm{hrs}$. and $</=10 \mathrm{hrs}$. 63.3\% of students had a screen time of $>10 \mathrm{hrs}$. /day. No significant association of screen time more than 10 hrs. /day was observed with gender and poorer sleep score. The average BMR calculated for the age and anthropometric parameters were higher in the students with screen time $</=10 \mathrm{hrs}$. per day but the difference was not significant. Calculated Caloric need for the group of students was observed to be almost similar and insignificant. Daily intake of calorie during the lockdown period was much higher than the recommended dietary allowance for the age and gender in both the groups. The calorie intake was higher in those with screen time $</=10 \mathrm{hrs}$. per day than those with $>10 \mathrm{hrs}$. but the difference was not significant. (Table 2)

Mean hours of actual sleep were about $5 \mathrm{hrs}$. and not significantly different between screen time of $>10$ and $</=10 \mathrm{hrs}$. As expected, mobile screen time in 24 hours was significantly higher in screen time $>10 \mathrm{hrs}$. Both the groups denied excessive eating while watching any form of screen (\%). Most of the students with screen time $</=10 \mathrm{hrs}$. watched the screen more in the night (\%) whereas those with screen time $>10 \mathrm{hrs}$. watched the screen in day (\%) \& night (\%). Students rated their sleep quality fairly good (\%) and were significantly associated with the screen time less than equal to 10 although their sleep time extended in the morning hours. Duration of 5 and less hours of sleep was observed in students with screen time of $>10$ hrs per day and the score was lesser among them. Sleep efficiency score was more than equal to 2 in students with screen time $>10 \mathrm{hrs}$ per day, which was statistically significant. Although the global score of PSQI for sleep was observed to be indifferent between the groups but was higher suggesting poor sleep pattern (score of 7).(21) Poor PSQI score $>5$ was significantly associated with Screen time $>10$ hrs (Chi 4.26; $\mathrm{p}=0.039$ ). (Table 3 )

The relation of screen time per day with statistically significant dependent variables of sleep and calorie intake is shown in. (Table 4) Screen time per day was significantly and positively related to sleep duration score [ more score means less sleep duration ( $5 \mathrm{hrs} \&$ less)] $r=0.313 ; p=0.015$ and sleep efficiency score [high score means poorer sleep efficiency (65\% \&less)] $r=0.462 ; p=0.005$. PSQI score of sleep though positively related to the screen time but is not statistically significant. Screen time was negatively related to daily calorie intake though insignificant. Sleep duration and efficiency scores were negatively but insignificantly related to calorie intake. BMI was negatively related to sleep efficiency and calorie intake but positively to Screen time though nonsignificant.

\section{Discussion}

The unprecedented pandemic of COVID-19 and the Implementation of staying indoors during lockdown have affected the adolescent group with extensive activity including academics, sports and social interactions. Initiation of online academic activity during lockdown has increased their screen time on electronic laptops, tablets and mobile phones, etc. 
Light is known to affect the daily circadian rhythm of body process, the study observed a higher mean screen time of $10 \mathrm{hrs} /$ day among adolescents with increased calorie intake and poorer sleep quality [higher PSQI score] during the lockdown in this pandemic.

The average age of the study participants was $20.43+/-1.35$ yrs. With similar proportion of males and females. Restricted to their houses and with online academics, $36.6 \%$ of the participants had a BMI more than $23 \mathrm{Kg} / \mathrm{m} 2$ which is much higher than that reported in North Indian undergraduate students (10.9\%) during the working of college. (22) $80 \%$ of the students had a poor sleep PSQI score of $>5$ with females having a higher proportion than males. This is higher than Indian medical students, where two out of ten medical students suffered from poor sleep quality (23) and $62.6 \%$ of the Indian undergraduate students (24) with female preponderance. Our study results of poor sleep among the college going students during their stay at home and online studies is twice than $40-55 \%$ reported by Gurjeet Kaur et al. in Indian undergraduates (22) and Malaysian university (25) but similar to that observed by Thai university (26) and but less than that in Brazil (27) (96.4\%) and Taiwanese university (28) studies all conducted during the working college. Gender showed no significant association with PSQI in the study, which is similar to that observed in Indian medical undergraduate students (15) which had a lower proportion [49.8\%] with poor sleep quality.

Adolescents of 19-29 years use gadgets regularly before trying to sleep and with an average of 8 to 9 hours of sleep each night to function adequately $(29,30)$ with $27 \%$ of students are at risk of sleep disorders (31). Sleep disturbance increases with light emitting devices including cell phone laptops and computers TV and gaming console (32) with poor academic learning (33) and at bedtime leading to a phase delay with slowing melatonin secretion, (34) finally affecting circadian of sleep \& food intake. In our study, average duration of sleep was 5.5 hours within subjective sleep duration of $4-10 \mathrm{hrs}$ as reported in several studies from Southern India [3.87 hrs] (15) and Northern Indian college [7.65hrs].(22) $38.8 \%$ of students use screen maximum during the night leading to sleeping late in the night and wake up late, corroborating to the trend of sleeping late and getting up late prevalent in college students. The study observed that $86.6 \%$ of students have the sleep for $<7$ hours and $46.6 \%$ having sleep of $<5$ hours during the lockdown phase of the pandemic which is more than that reported by Gurjeet et al.(22 ) [75.9\% more than $7 \mathrm{hrs}$ and $2.8 \%$ slept $<5 \mathrm{hrs}$ ] in Indian college students during regular college life. $36 \%$ of students taking $>30$ min to fall sleep in our study may be due to maximum screen time during night-time in them for the physiologic effect of light on the secretion of sleep hormone (35) which is less than undergraduate Indian students during routine college [70\% students] (22) and similar to American university [34.5\% < $5 \mathrm{hrs}$ ] (36) with $37.1 \%$ require $>30$ min or more to fall sleep. Poor PSQI score was significantly associated with Screen time $>10 \mathrm{hrs}$ (Chi 4.26; $p=0.039$ ), which is similar to a study by Natarajan et al. (15) in adolescents that observed a positive and significant relationship between poor quality PSQI and screen time [ $r=0.374]$.

$63.3 \%$ of the college students had a screen time $>10$ hours per day with $34.2 \%$ having higher screen time during the night. The subjective response of fairly good sleep quality rated by the students was significantly associated with screen time $<10$ hours /day \& sleep duration and efficiency were significantly poor in those with screen time $>10$ hours /day [higher sleep duration and efficiency score]. Although Poor Sleep quality indexed by PSQI of $</=$ to 5 (37) was observed in $66.2 \%$ of college students, no difference of mean sleep quality score [score 1] among those with $</=10 \mathrm{hrs} \&$ with $>10 \mathrm{hrs}$ of sleep was observed. Results are similar to American students with $58 \%$ having average, poor and very poor sleep quality but with mean sleep quality score of 2.39.(36) Students took equal time to sleep irrespective of screen time, although duration of sleep was significantly decreased in those with screen time $>10 \mathrm{hrs}$, which extended into the morning period in $45 \%$ of the students [ $9 \mathrm{AM}$ and beyond]. With average 5-6 hrs of sleep actual Hours of sleep as the proportion of hrs on the bed was significantly less in those with screen time $>10 \mathrm{hrs}$ [sleep efficiency of only 65\%] which is due to screen watching more at night which may be causing a physiological delay in the rise of sleep hormone due to the light emitted from the screen extending its peak (37)extending sleep into next day. A total of $41.6 \%$ of students woke up at night two or more times per week primarily due to an urge to use the bathroom [16.6\%] and bad dreams [18.3\%]. Our results are less than those in American college (36) [74.4\%], Palestinian University (37) [ 64.8\% with 
INDIAN JOURNAL OF COMMUNITY HEALTH / VOL 33 / ISSUE NO 01 / JAN- MAR 2021

more than one awakening] and Indian undergraduates (22) but with the same reason for awakening. Hence young adults tend to be more awake in the evening hours; along with that, they have difficulty in sleep initiation and insufficient sleep during the night and with daytime sleepiness. (38) Blue wavelengths emitted from the screen are beneficial during daylight hours, boosting attention, reaction times, and mood but are most disruptive at night, upsetting their sleep, food metabolism, and hormonal release extending the circadian in people who stay up late.

Apart from disruption of the sleep cycle, light exposure in evening and night also makes an impact on hunger and metabolism by affecting the hepatic circadian system and via physiological arousal altering appetite, (39) circulating glucose (40) and feeding behaviour due to release of hormones and decrease in Leptin (41) [hormone of satiety]. The modifiable risk factors of dietary intake and physical inactivity are important contributory factors to weight gain during college (42) due to all-you-caneat facilities, evening snaking; which alter their dietary behaviour and may cause weight gain. (43) Our study observed overweight /obesity in $46 \%$ of college-going students but BMI was not related to screen time and increased calorie intake. Screen viewing per day contributes to $42 \%$ of the daily intake in adolescents (44) with the contribution of more sugars and sweetened beverages. Calorie intake can be affected by screen time by overeating due to distraction,(45) unhealthy food marketing (46) and reduced physical activity.(45) Observational $(47,48)$ and systemic review $(49)$ studies have linked the prolonged sedentary time especially of watching screen to the increased risk of obesity with a short sleep duration of $<10 \mathrm{hrs}$. is associated with weight gain and obesity in adolescents.

Daily intake of calorie was much higher [10 times] than the recommended dietary allowance for the age and gender among college students but only $13.3 \%$ committed to eating in excess while watching screen. Although high proportion of calories and eating occasionally consumed while on screen viewing in adolescents (44) participants in our study subjectively answered no to such contribution. The negative association of screen time with the calorie intake in college-going students with mean BMI of $>23 \mathrm{~kg} / \mathrm{m} 2$ [overweight] in our study is contrary to the high intake of calories observed on long term screening in Chinese overweight children (extra of

$136 \mathrm{kcal} / \mathrm{day})(50)$ and to the short term experimental studies even in healthy weighted youth. $(51,52)$ The negative correlation of sleep duration and efficiency with calorie intake in our study $(r=-0.29)$ is similar to that reported by Reid et al (53) but was insignificant. In our study, high dietary intake during lockdown could be due to their presence at their respected home with parental influence,(54) family culture of eating pattern in Indian home compounded by an extended time of activity and less sleep hours of the average of $5 \mathrm{hrs}$. per day due to online academic and social activity (55) during the current pandemic.

\section{Conclusion}

The study concludes that average screen time of students of age group 18-24 years have increased during night under the lockdown. This extended viewing in night has shifted the sleep circadian cycle to morning hours, with daytime sleepiness and poor sleep quality. The high calorie intake was also observed in students during lockdown though no correlation was established with the screen time and sleep quality.

\section{Recommendation}

It becomes important for us to create awareness about sleep among students, parents and other stakeholders. It is also crucial to regulate their screen time \& dietary habits so that they lead a healthy life presently and in future. It may be recommended that students should not disturb their circadian cycle as it will affect their health and may lead to some common lifestyle related diseases in future.

\section{Limitation of the study}

The study was done on a smaller number of subject due to the use of an elaborate questionaries on a digital platform which was proportionally difficult to access and monitor. Since some of the questions were subjective and were on recall basis, the result of the study must be viewed by the reader in that context. It is essential that we consider the fact that most of the individuals happens to multi-watch at a particular time, therefore, it is possible that while operating one gadget they may be using another gadget simultaneously.

\section{Relevance of the study}

COVID pandemic had a paradigm shift of student's academics from offline to online platform which has increased their hours of screen time spent on both 
academics and social interactions which is likely to affect their biological cycle of sleep and eating pattern.

With $50 \%$ of students sleeping less than recommended 5 hours of sleep and irregular increased calorie intake vis a viz less physical activity they are likely to have sleep disorders and may develop psychosocial \& medical illness in long run.

\section{Authors Contribution}

RS- Contributed to conception, acquisition of data, or analysis and interpretation of data; drafting the article. NP- Acquisition of data and drafting the article. PK- Acquisition of data and drafting the article. TA- Contributed to conception and design, interpretation of data; revising it critically for important intellectual content and final approval of the version to be published.

\section{Acknowledgement}

The authors would like to acknowledge Dr. Yogesh Saxena, Professor in Physiology, Himalayan Institute of Medical Sciences, Dehradun for providing valuable inputs during statistical analysis.

\section{References}

1. Schupp M, Hanning CD. Physiology of sleep. Bja Cepd Reviews. 2003;3(3):69-74.

2. Edinger JD, Bonnet $M H$, Bootzin RR, Doghramji K, Dorsey $\mathrm{CM}$, Espie CA, Jamieson AO, McCall WV, Morin CM, Stepanski EJ; American Academy of Sleep Medicine Work Group. Derivation of research diagnostic criteria for insomnia: report of an American Academy of Sleep Medicine Work Group. Sleep. 2004;27(8):1567-96. doi: 10.1093/sleep/27.8.1567. PMID: 15683149.[PubMed].

3. Hyyppä MT, Kronholm E. Quality of sleep and chronic illnesses. J Clin Epidemiol. 1989;42(7):633-8. doi: 10.1016/0895-4356(89)90006-1. PMID: 2788211.[PubMed].

4. Haba-Rubio J, Marques-Vidal $P$, Andries $D$, Tobback $N$, Preisig M, Vollenweider P, Waeber G, Luca G, Tafti M, Heinzer R. Objective sleep structure and cardiovascular risk factors in the general population: the HypnoLaus Study. Sleep. 2015;38(3):391-400. doi: 10.5665/sleep.4496. PMID: 25325467; PMCID: PMC4335515.[PubMed].

5. Ruiter Petrov ME, Letter AJ, Howard VJ, Kleindorfer D. Selfreported sleep duration in relation to incident stroke symptoms: nuances by body mass and race from the REGARDS study. J Stroke Cerebrovasc Dis. 2014;23(2):e12332. doi: 10.1016/j.jstrokecerebrovasdis.2013.09.009. Epub 2013 Oct 8. PMID: 24119626; PMCID: PMC3946730.[PubMed].

6. Aldabal L, Bahammam AS. Metabolic, endocrine, and immune consequences of sleep deprivation. Open Respir Med J. 2011;5:31-43. doi: 10.2174/1874306401105010031. Epub 2011 Jun 23. PMID: 21754974; PMCID: PMC3132857.[PubMed].
, Christou S, Isherwood C, Middleton B, Gibbs MA, Archer SN, Skene DJ, Johnston JD. Meal Timing Regulates the Human Circadian System. Curr Biol. 2017;27(12):1768-1775.e3.

doi: 10.1016/j.cub.2017.04.059. Epub 2017 Jun 1. PMID: 28578930; PMCID: PMC5483233.[PubMed].

8. Akerstedt T, Hume K, Minors D, Waterhouse J. Good sleep-its timing and physiological sleep characteristics. J Sleep Res. 1997;6(4):221-9. doi: 10.1111/j.13652869.1997.00221.x. PMID: 9493521.[PubMed].

9. Vélez JC, Souza A, Traslaviña S, Barbosa C, Wosu A, Andrade A, Frye M, Fitzpatrick AL, Gelaye B, Williams MA. The Epidemiology of Sleep Quality and Consumption of Stimulant Beverages among Patagonian Chilean College Students. Sleep Disord. 2013;2013:910104. doi: 10.1155/2013/910104. Epub 2013 May 16. PMID: 23766919; PMCID: PMC3671558.[PubMed].

10. Brand S, Kirov R. Sleep and its importance in adolescence and in common adolescent somatic and psychiatric conditions. Int J Gen Med. 2011;4:425-42. doi: 10.2147/IJGM.S11557. Epub 2011 Jun 7. PMID: 21731894; PMCID: PMC3119585.[PubMed].

11. Hershner SD, Chervin RD. Causes and consequences of sleepiness among college students. Nat Sci Sleep. 2014;6:73-84. doi: 10.2147/NSS.S62907. PMID: 25018659; PMCID: PMC4075951.[PubMed].

12. Walker MP, van der Helm E. Overnight therapy? The role of sleep in emotional brain processing. Psychol Bull. 2009;135(5):731-48. doi: 10.1037/a0016570. PMID: 19702380; PMCID: PMC2890316.[PubMed].

13. Lemma S, Berhane $Y$, Worku A, Gelaye B, Williams MA. Good quality sleep is associated with better academic performance among university students in Ethiopia. Sleep Breath. 2014;18(2):257-63. doi: 10.1007/s11325-013-08748. Epub 2013 Aug 9. PMID: 23928956; PMCID: PMC3918486.[PubMed].

14. Gaultney JF. The prevalence of sleep disorders in college students: impact onacademic performance. J Am Coll Health. 2010;59(2):91-7 doi:10.1080/07448481.2010.483708. PMID: 20864434. [PubMed].

15. Natarajan A, Kanagamuthu R, Reddy MS, Sindhuja AS. Assessment of Influence of Screen Time on Quality of Sleep among Dental Students. Ann. Int. Med. Den. Res. 2020; 6(5):PH01-PH04.

16. Merriam-Webster "Screen time. " https://www.merriamwebster.com/dictionary/screen\%20time MerriamWebster.com Dictionary [accessed 24 Feb 2021]

17. Vizcaino $M$, Buman $M$, DesRoches $C T$, Wharton C. Reliability of a new measure to assess modern screen time in adults. BMC Public Health. 2019;19(1):1386. doi: 10.1186/s12889019-7745-6. PMID: 31660931; PMCID: PMC6816215.[Pubmed].

18. Ramirez ER, Norman GJ, Rosenberg DE, Kerr J, Saelens BE, Durant N, Sallis JF. Adolescent screen time and rules to limit screen time in the home. J Adolesc Health. 2011;48(4):37985. doi: 10.1016/j.jadohealth.2010.07.013. Epub 2010 Oct 15. PMID: 21402267; PMCID: PMC3058142.[PubMed].

19. Buysse DJ, Reynolds CF 3rd, Monk TH, Berman SR, Kupfer DJ. The Pittsburgh Sleep Quality Index: a new instrument for psychiatric practice and research. Psychiatry Res. 

1989;28(2):193-213. doi: 10.1016/0165-1781(89)90047-4. PMID: 2748771.[PubMed].

20. Telles S, Bhardwaj AK, Gupta RK, Kumar A, Balkrishna A. Development of a food frequency questionnaire to assess dietary intake for the residents of the Northern Region of India. Indian Journal of Ancient Medicine and Yoga. 2016;9(4): PAGE NO.

21. Buysse DJ, Hall ML, Strollo PJ, Kamarck TW, Owens J, Lee L, Reis SE, Matthews KA. Relationships between the Pittsburgh Sleep Quality Index (PSQI), Epworth Sleepiness Scale (ESS), and clinical/polysomnographic measures in a community sample. J Clin Sleep Med. 2008;4(6):563-71. Erratum in: J Clin Sleep Med. 2010 Feb 15;6(1):table of contents. PMID: 19110886; PMCID: PMC2603534.[PubMed].

22. Kaur G, A Study on the Sleep Quality of Indian College Students. JSM Brain Sci 2018;3(1): 1018.

23. Chutani A, Shenvi DN, Singhal A. Sleep, sleepiness and medical college students: a comparative study among medical and paramedical students of a tertiary care teaching hospital from a west Indian Metropolitan City. Annals of Medical and Health Sciences Research. 2017;7(2):85-91.

24. Shad R, Thawani R, Goel A. Burnout and Sleep Quality: A Cross-Sectional Questionnaire-Based Study of Medical and Non-Medical Students in India. Cureus. 2015;7(10):e361. doi: 10.7759/cureus.361. PMID: 26623216; PMCID: PMC4659578.[PubMed])

25. Lai PP, Say YH. Associated Factors of Sleep Quality and Behavior among Students of Two Tertiary Institutions in Northern Malaysia. Med J Malaysia. 2013;68(3):195-203. PMID: 23749006.[PubMed].

26. Lohsoonthorn V, Khidir H, Casillas G, Lertmaharit S, Tadesse MG, Pensuksan WC, Rattananupong T, Gelaye B, Williams MA. Sleep quality and sleep patterns in relation to consumption of energy drinks, caffeinated beverages, and other stimulants among Thai college students. Sleep Breath. 2013;17(3):1017-28. doi: 10.1007/s11325-0120792-1. Epub 2012 Dec 14. PMID: 23239460; PMCID: PMC3621002.[PubMed].

27. Cates ME, Clark A, Woolley TW, Saunders A. Sleep quality among pharmacy students. Am J Pharm Educ. 2015;79(1):09. doi: 10.5688/ajpe79109. PMID: 25741025; PMCID: PMC4346821.[PubMed]

28. Cheng SH, Shih CC, Lee IH, Hou YW, Chen KC, Chen KT, Yang YK, Yang YC. A study on the sleep quality of incoming university students. Psychiatry Res. 2012;197(3):270-4. doi: 10.1016/j.psychres.2011.08.011. Epub 2012 Feb 18. PMID: 22342120. [PubMed].

29. Hirshkowitz M, Whiton K, Albert SM, Alessi C, Bruni O, DonCarlos L, Hazen N, Herman J, Katz ES, Kheirandish-Gozal L, Neubauer DN, O'Donnell AE, Ohayon M, Peever J, Rawding R, Sachdeva RC, Setters B, Vitiello MV, Ware JC, Adams Hillard PJ. National Sleep Foundation's sleep time duration recommendations: methodology and results summary. Sleep Health. 2015;1(1):40-43. doi: 10.1016/j.sleh.2014.12.010. Epub 2015 Jan 8. PMID: 29073412. [PubMed].

30. Hysing M, Pallesen S, Stormark KM, Jakobsen R, Lundervold AJ, Sivertsen B. Sleep and use of electronic devices in adolescence: results from a large population-based study. BMJ Open. 2015;5(1):e006748. doi: 10.1136/bmjopen-

2014-006748. Pffect of Screen...] | Saxena R et al
PMID: $25643702 ; \quad$ PMCID: PMC4316480.[PubMed].

31. Gaultney JF. The prevalence of sleep disorders in college students: impact on academic performance. J Am Coll Health. 2010;59(2):91-7. doi: 10.1080/07448481.2010.483708. PMID: 20864434. [PubMed].

32. Jones MJ, Peeling P, Dawson B, Halson S, Miller J, Dunican I, Clarke M, Goodman C, Eastwood P. Evening electronic device use: The effects on alertness, sleep and next-day physical performance in athletes. J Sports Sci. 2018;36(2):162-170. doi: 10.1080/02640414.2017.1287936. Epub 2017 Feb 14 PMID: 28282750.[PubMed].

33. Hobson JA, Pace-Schott EF. The cognitive neuroscience of sleep: neuronal systems, consciousness and learning. Nat Rev Neurosci. 2002;3(9):679-93. doi: 10.1038/nrn915. PMID: 12209117.[PubMed].

34. Chang AM, Aeschbach D, Duffy JF, Czeisler CA. Evening use of light-emitting eReaders negatively affects sleep, circadian timing, and next-morning alertness. Proc Natl Acad Sci U S A. 2015;112(4):1232-7. doi: 10.1073/pnas.1418490112. Epub 2014 Dec 22. PMID: 25535358; PMCID: PMC4313820.[PubMed].

35. Blume C, Garbazza C, Spitschan M. Effects of light on human circadian rhythms, sleep and mood. Somnologie (Berl). 2019;23(3):147-156. doi: 10.1007/s11818-019-00215-x. Epub 2019 Aug 20. PMID: 31534436; PMCID: PMC6751071.[PubMed].

36. Sargent, Angela Lynn, "Screen Time and Sleep Condition among Selected College Students". All Theses, Dissertations, and Other Capstone Projects. 681. http://cornerstone.lib.mnsu.edu/etds/681 (2017).

37. Famodu OA, Barr ML, Holásková I, Zhou W, Morrell JS, Colby SE, Olfert MD. Shortening of the Pittsburgh Sleep Quality Index Survey Using Factor Analysis. Sleep Disord. 2018;2018:9643937. doi: 10.1155/2018/9643937. PMID: 29850262; PMCID: PMC5925150.[PubMed].

38. Araújo MF, Lima AC, Araújo TM, Veras VS, Zanetti ML, Damasceno MM. Association of sociodemografic factors and sleep quality in brazilian university students. Texto \& Contexto-Enfermagem. 2014;23(1):176-84.

39. Reid KJ, Santostasi G, Baron KG, Wilson J, Kang J, Zee PC. Timing and intensity of light correlate with body weight in adults. PLoS One. 2014;9(4):e92251. doi: 10.1371/journal.pone.0092251. PMID: 24694994; PMCID: PMC3973603.[PubMed].

40. Ishida A, Mutoh T, Ueyama $T$, Bando $H$, Masubuchi $S$, Nakahara D, Tsujimoto G, Okamura H. Light activates the adrenal gland: timing of gene expression and glucocorticoid release. Cell Metab. 2005;2(5):297-307. doi: 10.1016/j.cmet.2005.09.009. PMID: 16271530.[PubMed].

41. Harvard Health. Blue light has a dark side. Retrieved from http://www.health.harvard.edu/staying-healthy/bluelight-has-a-dark-side (2016).

42. Whisner CM, Maldonado J, Dente B, Krajmalnik-Brown R, Bruening M. Diet, physical activity and screen time but not body mass index are associated with the gut microbiome of a diverse cohort of college students living in university housing: a cross-sectional study. BMC Microbiol. 2018;18(1):210. doi: 10.1186/s12866-018-1362-x. PMID: 30541450; PMCID: PMC6291939.[PubMed]:210-Page no. 
INDIAN JOURNAL OF COMMUNITY HEALTH / VOL 33 / ISSUE NO 01 / JAN- MAR 2021

43. 43. Demory-Luce $D$, Morales $M$, Nicklas $T$, Baranowski $T$, Zakeri I, Berenson G. Changes in food group consumption patterns from childhood to young adulthood: the Bogalusa Heart Study. Journal of the American Dietetic Association. 2004;104(11):1684-91[PubMed].

44. Taillie LS, Jensen ML, Carpentier FD, Corvalán C, Popkin BM, Evenson K, Adair L. Screen time and eating during screen time: associations with dietary intake in children and adolescents. DOI: 10.21203/rs.2.21352/v1 [Pre-print]. $2020 . \quad$ Available from: https://www.researchsquare.com/article/rs-11946/v1

45. Gebremariam MK, Bergh IH, Andersen LF, Ommundsen $Y$, Totland TH, Bjelland M, Grydeland M, Lien N. Are screenbased sedentary behaviors longitudinally associated with dietary behaviors and leisure-time physical activity in the transition into adolescence? Int J Behav Nutr Phys Act. 2013;10:9. doi: 10.1186/1479-5868-10-9. PMID: 23351357; PMCID: PMC3560151.[PubMed].

46. Lobstein T, Dibb S. Evidence of a possible link between obesogenic food advertising and child overweight. Obes Rev. 2005;6(3):203-8. doi: 10.1111/j.1467789X.2005.00191.x. PMID: 16045635.[PubMed].

47. Leech RM, McNaughton SA, Timperio A. The clustering of diet, physical activity and sedentary behavior in children and adolescents: a review. Int J Behav Nutr Phys Act. 2014;11:4. doi: 10.1186/1479-5868-11-4. PMID: 24450617; PMCID: PMC3904164.[PubMed]

48. Cappuccio FP, Taggart FM, Kandala NB, Currie A, Peile E, Stranges S, Miller MA. Meta-analysis of short sleep duration and obesity in children and adults. Sleep. 2008;31(5):61926. doi: 10.1093/sleep/31.5.619. PMID: 18517032; PMCID: PMC2398753.[PubMed].

49. Ruan $H$, Xun $P$, Cai W, He K, Tang Q. Habitual Sleep Duration and Risk of Childhood Obesity: Systematic Review and Dose-response Meta-analysis of Prospective Cohort
[Effect of Screen...] | Saxena R et al Studies. Sci Rep. 2015;5:16160. doi: 10.1038/srep16160. PMID: 26537869; PMCID: PMC4633618. [PubMed].

50. Shang L, Wang J, O'Loughlin J, Tremblay A, Mathieu MÈ, Henderson M, Gray- Donald K. Screen time is associated with dietary intake in overweight Canadian children. Prev Med Rep. 2015;2:265-9. doi: 10.1016/j.pmedr.2015.04.003. PMID: 26844082; PMCID: PMC4721420.[PubMed].

51. Epstein LH, Roemmich JN, Robinson JL, Paluch RA, Winiewicz DD, Fuerch JH, Robinson TN. A randomized trial of the effects of reducing television viewing and computer use on body mass index in young children. Arch Pediatr Adolesc Med. 2008;162(3):239-45. doi: 10.1001/archpediatrics.2007.45. PMID: 18316661; PMCID: PMC2291289.[PubMed].

52. Chaput JP, Visby T, Nyby S, Klingenberg L, Gregersen NT, Tremblay A, Astrup A, Sjödin A. Video game playing increases food intake in adolescents: a randomized crossover study. Am J Clin Nutr. 2011;93(6):1196-203. doi: 10.3945/ajcn.110.008680. Epub 2011 Apr 13. PMID: 21490141.[PubMed].

53. Reid KJ, Baron KG, Zee PC. Meal timing influences daily caloric intake inhealthy adults. Nutr Res. 2014;34(11):9305. doi:10.1016/j.nutres.2014.09.010. Epub 2014 Oct 2. PMID: 25439026; PMCID:PMC4794259.[PubMed].

54. Savage JS, Fisher JO, Birch LL. Parental influence on eating behavior: conception to adolescence. J Law Med Ethics. 2007;35(1):22-34. doi: 10.1111/j.1748-720X.2007.00111.x. PMID: 17341215; PMCID: PMC2531152.[PubMed].

55. Chadda RK, Deb KS. Indian family systems, collectivistic society and psychotherapy. Indian J Psychiatry. 2013;55(Suppl 2):S299-309. doi: 10.4103/00195545.105555. PMID: 23858272; PMCID: PMC3705700.[PubMed]

\section{Tables}

TABLE 1 DEMOGRAPHIC, ANTHROPOMETRIC, DAILY CALORIC INTAKE, SLEEP INDICES \& SCREEN TIME PROFILE OF COLLEGE GOING STUDENTS DURING ONLINE CLASSES IN COVID-19 PANDEMIC

\begin{tabular}{|c|c|c|}
\hline Parameters & \multicolumn{2}{|c|}{ Mean $\pm S . D(N=60)$} \\
\hline Age (yrs.) & \multicolumn{2}{|c|}{$20.43 \pm 1.35$} \\
\hline Gender & \multicolumn{2}{|c|}{$M=30 ; F=30$} \\
\hline Weight (Kg) & \multicolumn{2}{|c|}{$65.42 \pm 15.86$} \\
\hline Height(cm) & \multicolumn{2}{|c|}{$168.08 \pm 10.44$} \\
\hline $\mathrm{BMI}(\mathrm{Kg} / \mathrm{m} 2)$ & \multicolumn{2}{|c|}{$23.06 \pm 4.7$} \\
\hline - Underweight \& Normal <23 Kg/m2 & \multicolumn{2}{|c|}{$63.30 \%$} \\
\hline - Overweight $23-27.5 \mathrm{Kg} / \mathrm{m} 2$ & \multicolumn{2}{|c|}{$23.30 \%$} \\
\hline - Obese $>/=27.5 \mathrm{Kg} / \mathrm{m} 2$ & \multicolumn{2}{|c|}{$13.30 \%$} \\
\hline Calorie Intake/Day (cal/day) & \multicolumn{2}{|c|}{$15782.05 \pm 4462.48$} \\
\hline Extra Intake /Day (cal/day) & \multicolumn{2}{|c|}{$13872.5 \pm 4508.21$} \\
\hline \multirow[t]{2}{*}{ Excess eating during watching screen } & No & Yes \\
\hline & $56.60 \%$ & $13.30 \%$ \\
\hline Total Screen-Time /Day(hrs) & \multicolumn{2}{|c|}{$10.59 \pm 3.00$ [Range $5.4-16.8]$} \\
\hline \multirow[t]{2}{*}{ Maximum screen time } & Night & Evening \\
\hline & $38.30 \%$ & $13.30 \%$ \\
\hline \multirow[t]{2}{*}{ Actual hours of Sleep } & $<5$ hours & $<7$ hours \\
\hline & $46.60 \%$ & $86.60 \%$ \\
\hline
\end{tabular}


Global PSQI Score

$7.75 \pm 2.88$

- $\quad$ Sleep Quality

0.87

- $\quad$ Sleep Latency

1.27

- Sleep Duration

1.95

- Sleep efficiency

1.37

- $\quad$ Sleep Disturbance

1.35

- Day Dysfunction

0.95

TABLE 2 COMPARISON OF SLEEP INDEX AND CALORIC INTAKE ACROSS TOTAL SCREEN TIME IN COLLEGE STUDENTS DURING ONLINE CLASSES IN COVID-19 PANDEMIC

\begin{tabular}{|c|c|c|c|c|c|}
\hline & \multicolumn{2}{|c|}{ Screen-Time $</=10 \mathrm{hr} /$ day $(\mathrm{N}=22)$} & \multicolumn{2}{|c|}{ Screen-Time $>10$ ( $N=38)$} & \multirow[t]{2}{*}{ P-Value } \\
\hline & \multicolumn{2}{|c|}{$36.60 \%$} & \multicolumn{2}{|c|}{$63.30 \%$} & \\
\hline Age & \multicolumn{2}{|c|}{$20.34 \pm 1.5$} & \multicolumn{2}{|c|}{$20.59 \pm 1.05$} & 0.499 \\
\hline BMI & \multicolumn{2}{|c|}{$22.34 \pm 3.49$} & \multicolumn{2}{|c|}{$24.20 \pm 6.31$} & 0.158 \\
\hline *Daily Calorie Intake/Day & \multicolumn{2}{|c|}{$17048 \pm 5017.02$} & \multicolumn{2}{|c|}{$15049.13 \pm 3995.47$} & 0.095 \\
\hline BMR & \multicolumn{2}{|c|}{$1606.5 \pm 319.13$} & \multicolumn{2}{|c|}{$1582.32 \pm 256.9$} & 0.74 \\
\hline Calorie needed & \multicolumn{2}{|c|}{$1927.9 \pm 383.01$} & \multicolumn{2}{|c|}{$1898.8 \pm 308.3$} & 0.76 \\
\hline Extra Calorie Intake & \multicolumn{2}{|c|}{$15120 \pm 4973.19$} & \multicolumn{2}{|c|}{$13150.31 \pm 4016.56$} & 0.09 \\
\hline \multirow[t]{2}{*}{ \#Gender } & Male & Female & Male & Female & Chi=0.08; $d f=1$ \\
\hline & 9 & 13 & 21 & 17 & $P=0.77$ \\
\hline \# PSQI & & & & & Chi $=1.14 ; \mathrm{df}=1$ \\
\hline - $\quad</=5$ & & & & & $P=0.28$ \\
\hline - $\quad>5$ [Poor $]$ & & & & & \\
\hline " $t$ " Test; *Mann Whitney; & uare test & & & & \\
\hline
\end{tabular}

TABLE 3 COMPARISON OF SLEEP DETERMINANTS ACROSS TOTAL SCREEN TIME IN COLLEGE STUDENTS DURING ONLINE CLASSES IN COVID-19 PANDEMIC

\begin{tabular}{|c|c|c|c|c|c|}
\hline Sleep Determinants & \multicolumn{2}{|c|}{ Screen-Time $</=10(\mathrm{~N}=22)$} & \multicolumn{2}{|c|}{ Screen-Time $>10(N=38)$} & P-Value \\
\hline Hours of actual sleep/ day in last month & \multicolumn{2}{|c|}{$5.55+/-1.0$} & \multicolumn{2}{|c|}{$5.11+0.89$} & 0.085 \\
\hline \multirow[t]{2}{*}{ PSQI score } & $</=5$ & $>5$ & $</=5$ & $>5$ & \multirow[t]{2}{*}{ Chi $=4.26 p=0.039$} \\
\hline & 6 & 16 & 6 & 32 & \\
\hline Eat excessively while watching screen & & & & & Chi $=0.81$ \\
\hline - No & \multicolumn{2}{|l|}{13} & \multicolumn{2}{|c|}{26} & $\mathrm{Df}=2$ \\
\hline - Yes & \multicolumn{2}{|l|}{4} & \multicolumn{2}{|c|}{4} & $P=0.66$ \\
\hline - May be & \multicolumn{2}{|l|}{5} & \multicolumn{2}{|c|}{8} & \\
\hline Maximum screen time is during & & & & & Chi $=1.106$ \\
\hline - Day time & \multicolumn{2}{|l|}{8} & \multicolumn{2}{|c|}{14} & $\mathrm{Df}=2$ \\
\hline - $\quad$ Evening & \multicolumn{2}{|l|}{4} & \multicolumn{2}{|c|}{11} & $P=0.57$ \\
\hline - $\quad$ Night & \multicolumn{2}{|l|}{10} & \multicolumn{2}{|c|}{13} & \\
\hline Rate your sleep quality in past month? & & & & & Chi=8.66 \\
\hline - $\quad$ Bad & \multicolumn{2}{|l|}{2} & \multicolumn{2}{|c|}{7} & $d f=2$ \\
\hline - $\quad$ Fairly Good & \multicolumn{2}{|l|}{18} & \multicolumn{2}{|c|}{17} & $P=0.034^{*}$ \\
\hline - Very Good & \multicolumn{2}{|l|}{2} & \multicolumn{2}{|c|}{14} & \\
\hline \# Sleep Quality & \multicolumn{2}{|l|}{$1 \pm 0.43$} & \multicolumn{2}{|c|}{$0.79 \pm 0.87$} & $P=0.096$ \\
\hline \#Sleep Latency & \multicolumn{2}{|l|}{$1.5 \pm 1.01$} & \multicolumn{2}{|c|}{$1.13 \pm 0.99$} & $P=0.153$ \\
\hline "Sleep Efficiency & \multicolumn{2}{|l|}{$1.64 \pm 0.65$} & \multicolumn{2}{|c|}{$2.13 \pm 0.77$} & $\mathrm{P}=0.003^{* *}$ \\
\hline \#Sleep Duration & \multicolumn{2}{|l|}{$0.59 \pm 1.0$} & \multicolumn{2}{|c|}{$1.82 \pm 1.2$} & $\mathrm{P}=0.001^{* *}$ \\
\hline \#Sleep Disturbance & \multicolumn{2}{|l|}{$1.5 \pm 0.96$} & \multicolumn{2}{|c|}{$1.26 \pm 0.60$} & $P=0.363$ \\
\hline "Daytime-Dysfunction & \multicolumn{2}{|l|}{$0.82 \pm 0.73$} & & & $P=0.569$ \\
\hline \#Global PSQI Score & $7.05 \pm 2.1$ & & & & $P=0.237$ \\
\hline
\end{tabular}


TABLE 4 CORRELATION OF SCREEN TIME WITH SIGNIFICANT SLEEP DETERMINANTS, BMI AND DAILY CALORIC INTAKE IN COLLEGE STUDENTS DURING ONLINE CLASSES IN COVID-19 PANDEMIC $(N=60)$

\begin{tabular}{|c|c|c|c|c|c|c|c|}
\hline & \multirow[t]{2}{*}{ BMI } & \multirow{2}{*}{$\begin{array}{l}\text { Screen- } \\
\text { Time }\end{array}$} & \multirow{2}{*}{$\begin{array}{c}\text { Sleep } \\
\text { Duration }\end{array}$} & \multirow{2}{*}{$\begin{array}{c}\text { Sleep } \\
\text { Efficiency }\end{array}$} & \multirow{2}{*}{$\begin{array}{l}\text { PSQI } \\
\text { Score }\end{array}$} & \multirow[t]{2}{*}{ Daily Intake } & Extra Calorie \\
\hline & & & & & & & Per Day \\
\hline \multirow[t]{2}{*}{ BMI } & \multirow[t]{2}{*}{1} & 0.103 & 0.178 & -0.025 & 0.045 & -0.024 & -0.024 \\
\hline & & $P=.45$ & $P=0.17$ & $P=0.85$ & $P=0.85$ & $P=0.85$ & $P=0.85$ \\
\hline \multirow[t]{2}{*}{ Screen-Time } & & \multirow[t]{2}{*}{1} & $0.313^{*}$ & $0.462^{* *}$ & 0.187 & -0.218 & -0.215 \\
\hline & & & $P=0.015$ & $P=0.005$ & $P=0.15$ & $P=0.095$ & $P=0.99$ \\
\hline \multirow[t]{2}{*}{ Sleep Duration } & & \multirow[t]{2}{*}{-} & \multirow[t]{2}{*}{1} & $0.584^{* *}$ & $0.52^{* *}$ & -0.087 & -0.107 \\
\hline & & & & $P=0.001$ & $P=0.001$ & $P=0.50$ & $P=0.42$ \\
\hline \multirow[t]{2}{*}{ Sleep Efficiency } & & \multirow[t]{2}{*}{-} & \multirow[t]{2}{*}{-} & \multirow[t]{2}{*}{1} & $0.53^{* *}$ & -0.136 & -0.151 \\
\hline & & & & & $P=0.001$ & $P=0.30$ & $P=0.24$ \\
\hline \multirow[t]{2}{*}{ PSQI Score } & & \multirow[t]{2}{*}{-} & \multirow[t]{2}{*}{-} & \multirow[t]{2}{*}{-} & \multirow[t]{2}{*}{1} & -0.013 & -0.02 \\
\hline & & & & & & $P=0.92$ & $P=0.84$ \\
\hline \multirow[t]{2}{*}{ Daily Intake } & & \multirow[t]{2}{*}{-} & \multirow[t]{2}{*}{-} & \multirow[t]{2}{*}{-} & \multirow[t]{2}{*}{-} & \multirow[t]{2}{*}{1} & $0.997^{* *}$ \\
\hline & & & & & & & $P=0.001$ \\
\hline Extra Calorie Per Day & & - & - & - & - & & 1 \\
\hline \multicolumn{8}{|c|}{ ** Correlation is significant at 0.01 level (two tailed): * Correlation significant at 0.05 level (Two Tailed) } \\
\hline
\end{tabular}

